Supporting Information

\title{
Oxygen-Delivering Polyfluorocarbon Nanovehicles Improve Tumor Oxygenation and Potentiate Photodynamic-Mediated Antitumor Immunity
}

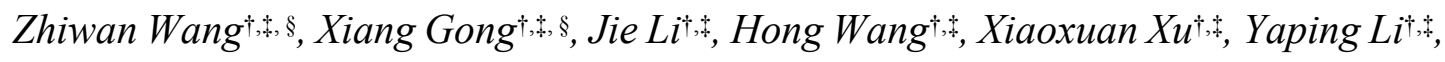
Xianyi Sha $a^{\sharp}$ Zhiwen Zhang ${ }^{\dagger,+,+, *}$

†. State Key Laboratory of Drug Research \& Center of Pharmaceutics, Shanghai Institute of Materia Medica, Chinese Academy of Sciences, Shanghai 201203, China

土, Yantai Key Laboratory of Nanomedicine \& Advanced Preparations, Yantai Institute of Materia Medica, Shandong, 264000, China.

$¥$ University of Chinese Academy of Sciences, Beijing 100049, China

\# School of Pharmacy, Fudan University, Shanghai, 201203, China

* Corresponding author: Prof. Zhiwen Zhang (zwzhang0125@simm.ac.cn) 


\section{Supplementary results:}

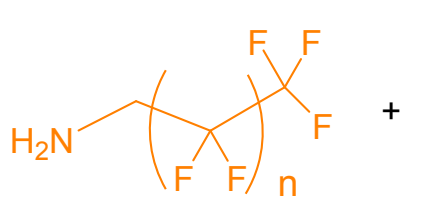

Perfluoroalkanes

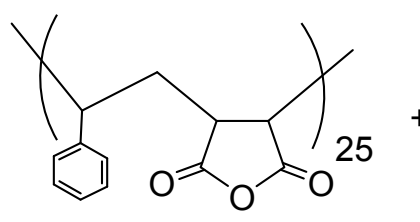

SMA<smiles>CC(C)OCCOC(C)(C)CN</smiles>

mPEG-NH
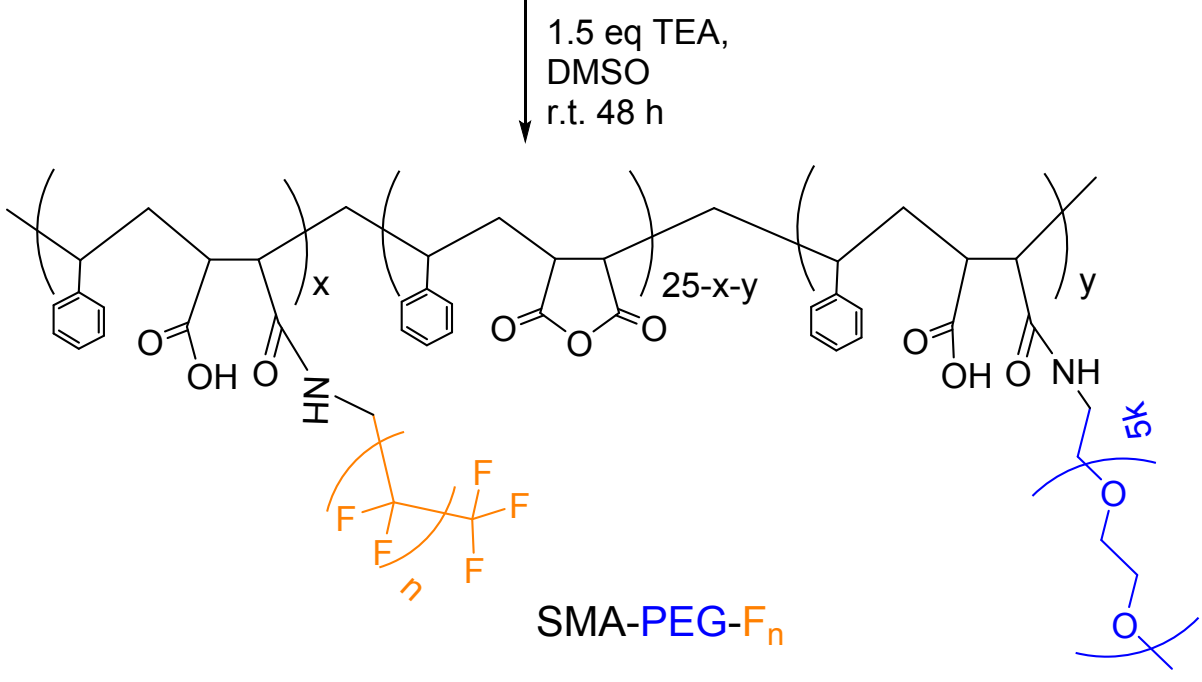

Figure S1 Synthesis of SMA-PEG-F $F_{n}$ SMA-PEG-F $F_{n}$ was synthesize by grafting perfluoroalkanes and mPEG-NH $\mathrm{N}_{2}$ to SMA at molar ratio of 8:4:1. These ingredients were dissolved in dimethyl sulfoxide (DMSO) with 1.5 eq of triethylamine (TEA) and kept at room temperature (r.t.) for 48 hours. Thereafter, the reaction mixture was purified with a dialysis method (14 KDa, 20535ES03, Yeasen) against deionized water and the purified solution was freeze-dried to obtain the SMA-PEG-F $\mathrm{n}_{\mathrm{n}}$ polymer. 

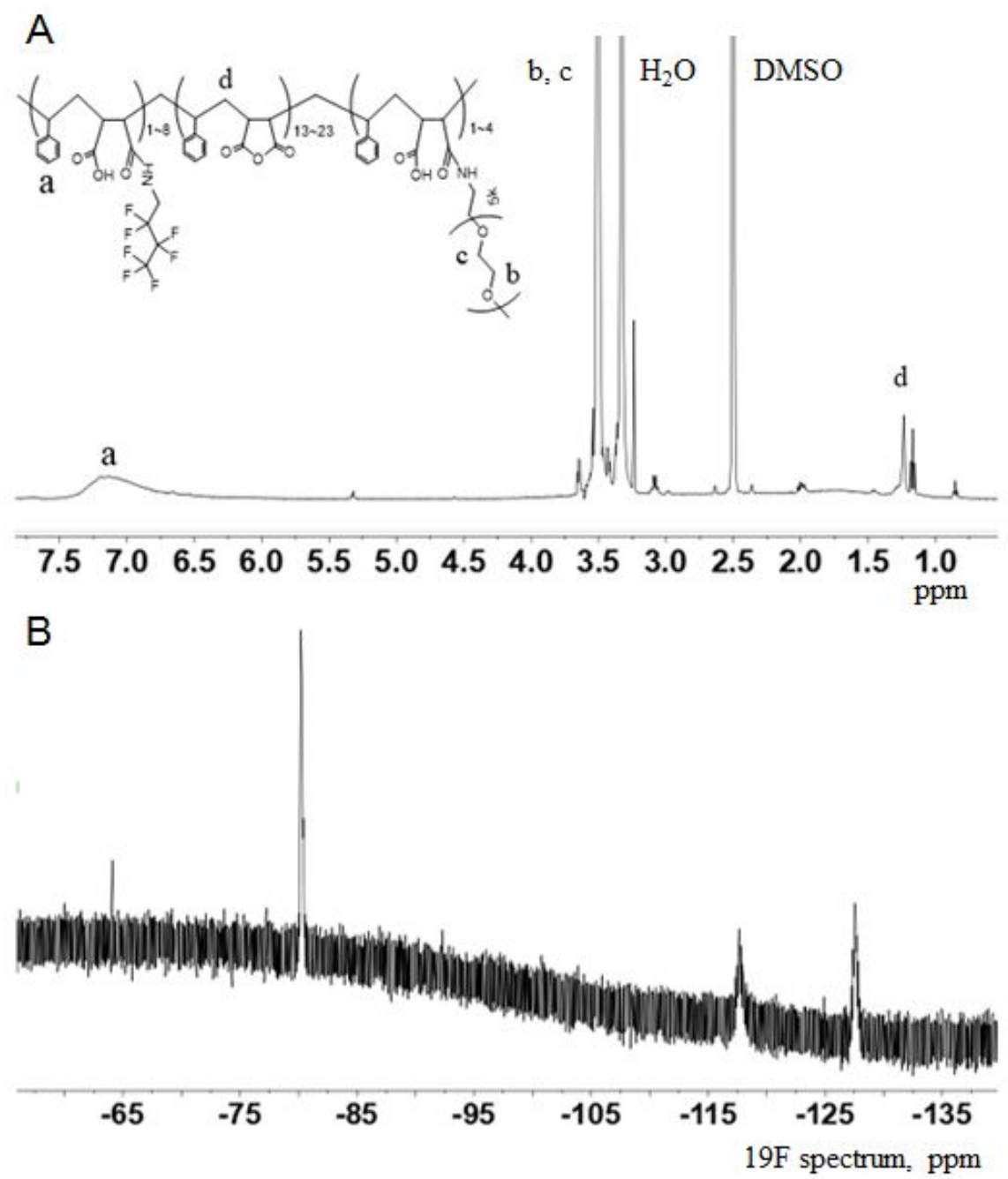

Figure S2 Characterization of SMA-PEG-F by $^{1} \mathrm{H}-\mathrm{NMR}$ and Fluorine spectra. 


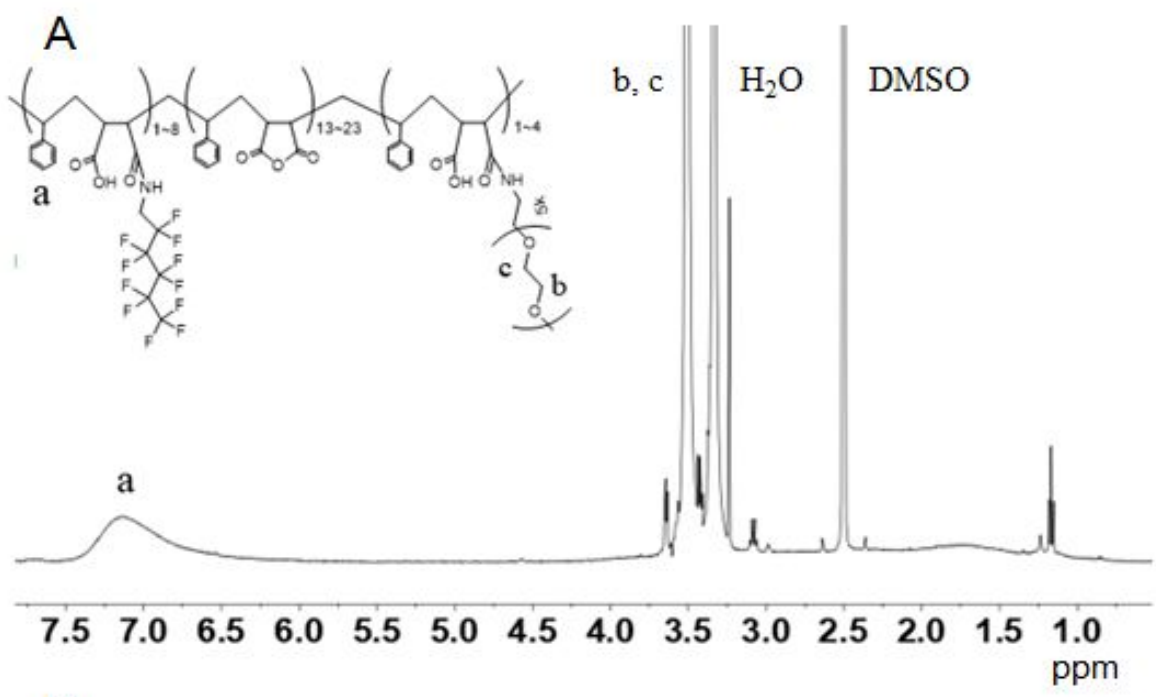

B

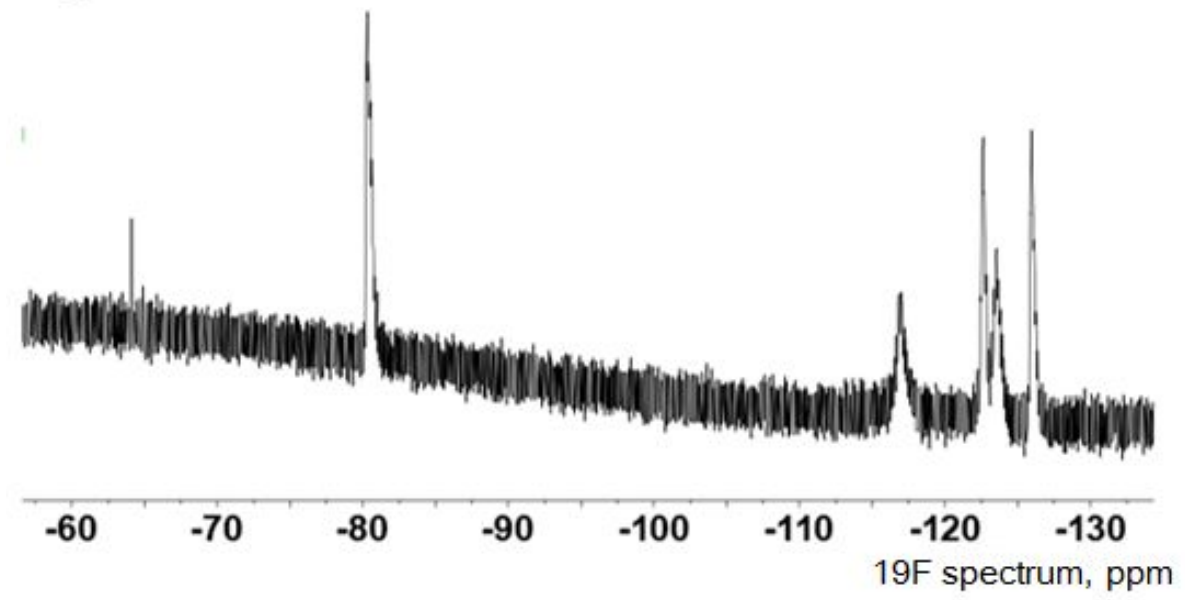

Figure S3 Characterization of SMA-PEG- $\mathrm{F}_{11}$ by ${ }^{1} \mathrm{H}-\mathrm{NMR}$ and Fluorine spectra. 

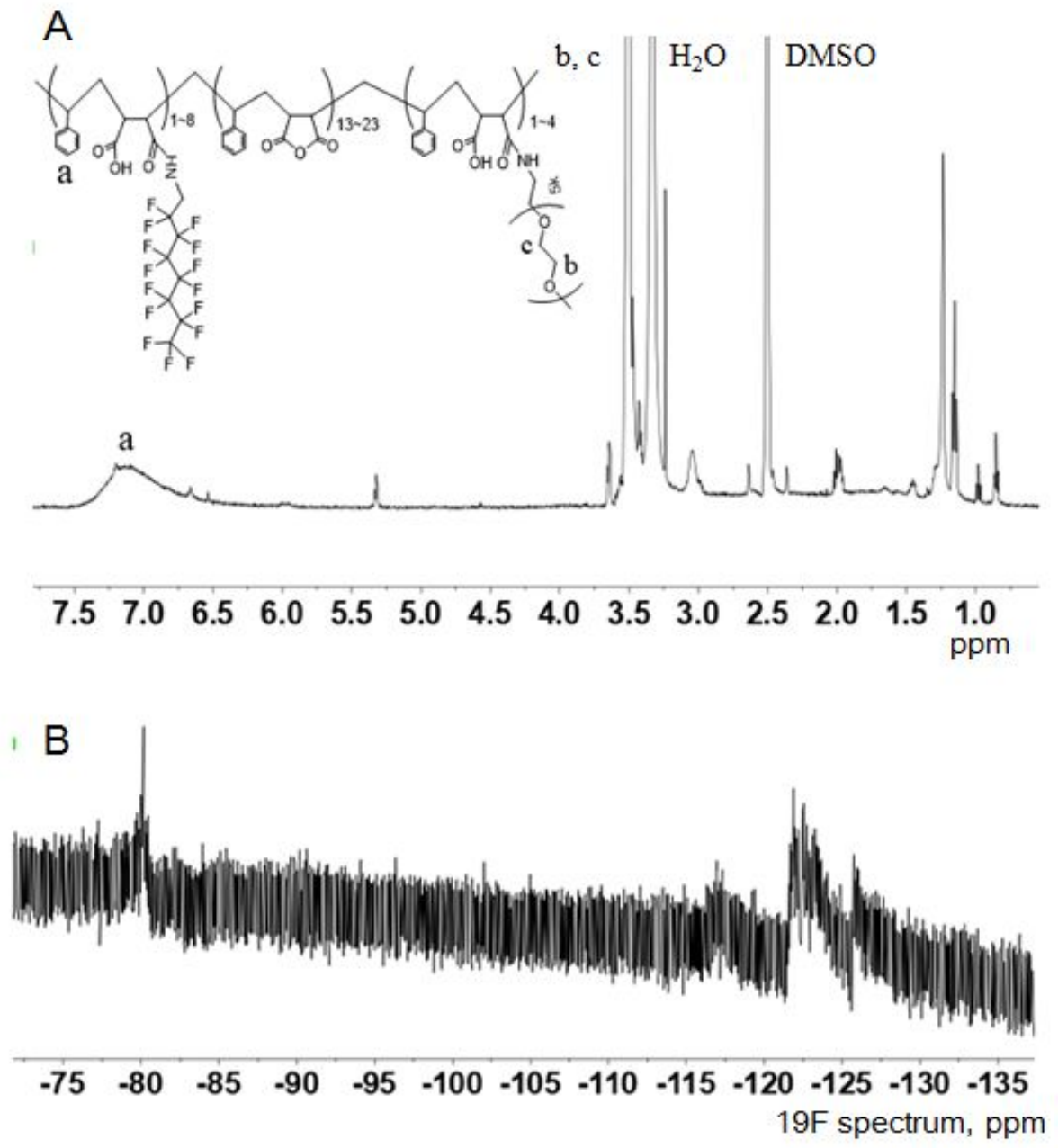

Figure S4 Characterization of SMA-PEG-F ${ }_{15}$ by ${ }^{1} \mathrm{H}-\mathrm{NMR}$ and Fluorine spectra.

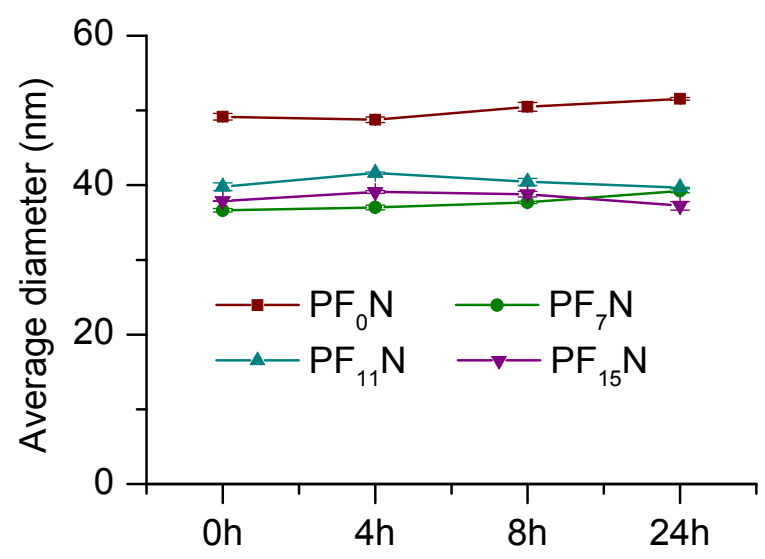

Figure S5 The mean diameter of four nanovehicles at different time points after incubation in PBS (pH 7.4) 
$\stackrel{\mathrm{O}}{\mathrm{COOH}} \underset{\mathrm{r.t,1 \textrm {h }}}{\stackrel{\mathrm{HCl}}{\longrightarrow}}$

HOOC

$\mathrm{TS}_{\mathrm{COOH}}$

Thioketal linker

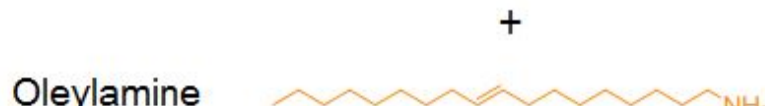

Oleylamine
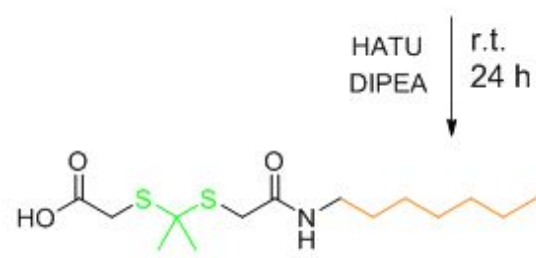

TK-OA
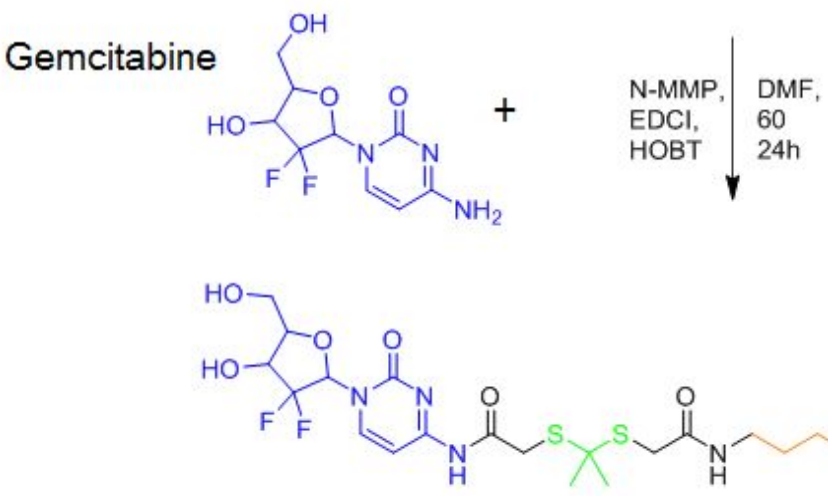

GTO

Figure S6 Synthesis of GTO. GTO was synthesized by conjugating oleylamine to gemcitabine with a thioketal linker. DIPEA ( $N, N$-Diisopropylethylamine); N-MMP $(N$ Methylmorpholine); EDCI (1-Ethyl-3-(3-dimethylaminopropyl)carbodiimide hydrochloride); HOBT (1-Hydroxybenzotriazole); DMF ( $N, N$-Dimethylformamide). The reaction mixture was purified on silica gel column with the eluant of ethyl acetate/methanol $(20: 1, \mathrm{v} / \mathrm{v})$ to obtain the desired product. 

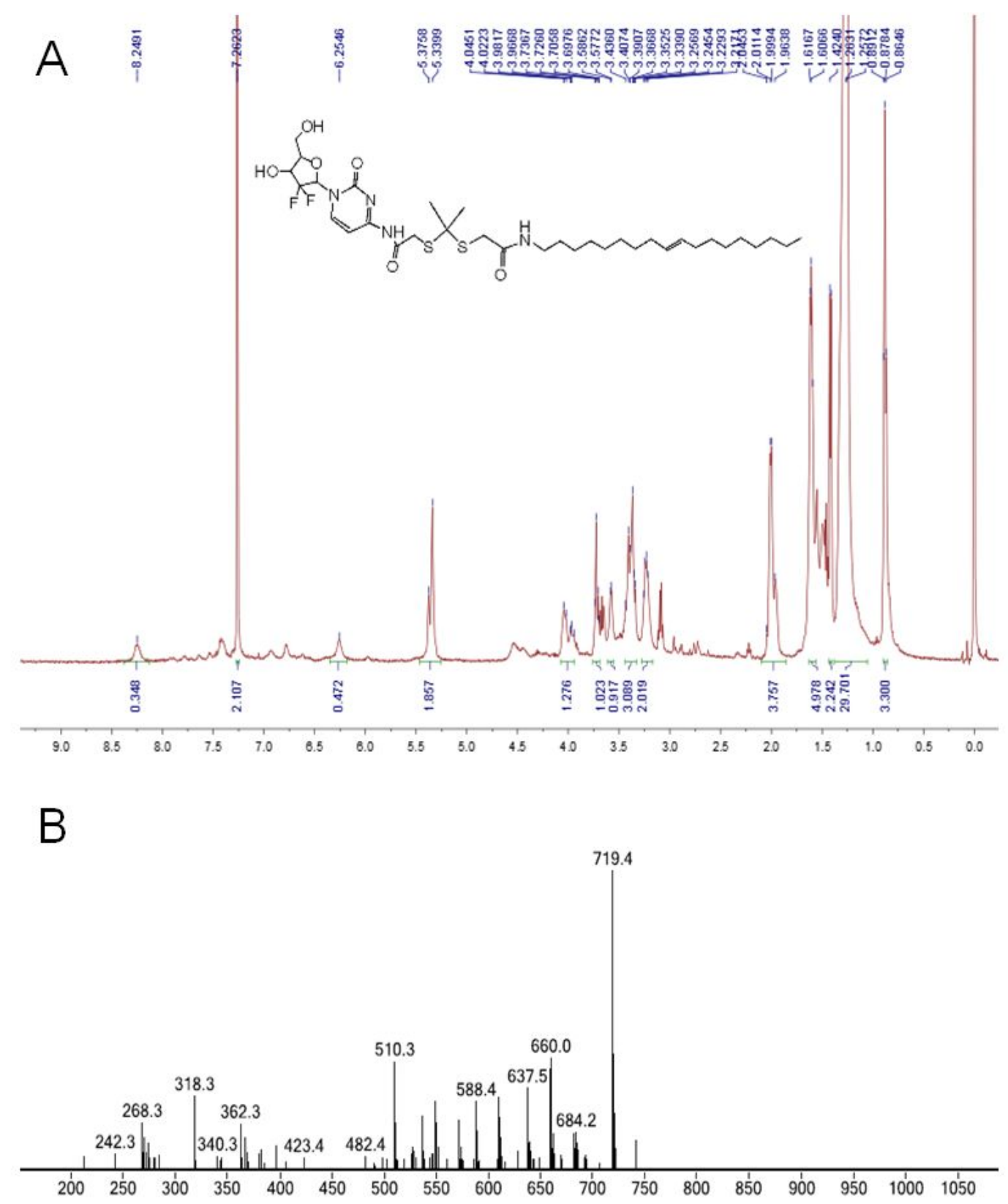

Figure S7 Characterization of GTO by ${ }^{1} \mathrm{H}-\mathrm{NMR}$ and Mass spectrum. (A) ${ }^{1} \mathrm{H}-\mathrm{NMR}$ $\left(500 \mathrm{MHz}, \mathrm{CDCl}_{3}\right) \delta 8.43-6.10(\mathrm{~m}, 2 \mathrm{H}), 5.36(\mathrm{~d},=18.0 \mathrm{~Hz}, 2 \mathrm{H}), 4.14-3.88(\mathrm{~m}, 1 \mathrm{H})$, $3.72(\mathrm{~m}, 1 \mathrm{H}), 3.58(\mathrm{~m}, 1 \mathrm{H}), 3.38(\mathrm{~m}, 3 \mathrm{H}), 3.24(\mathrm{~m}, 2 \mathrm{H}), 2.06-1.91(\mathrm{~m}, 4 \mathrm{H}), 1.65-$ $1.56(\mathrm{~m}, 5 \mathrm{H}), 1.42(\mathrm{~d}, J=6.5 \mathrm{~Hz}, 2 \mathrm{H}), 1.26(\mathrm{~m}, 30 \mathrm{H}), 0.88$ (t, $J=6.7 \mathrm{~Hz}, 3 \mathrm{H})$. (B) ESIMS spectrum of GTO. 


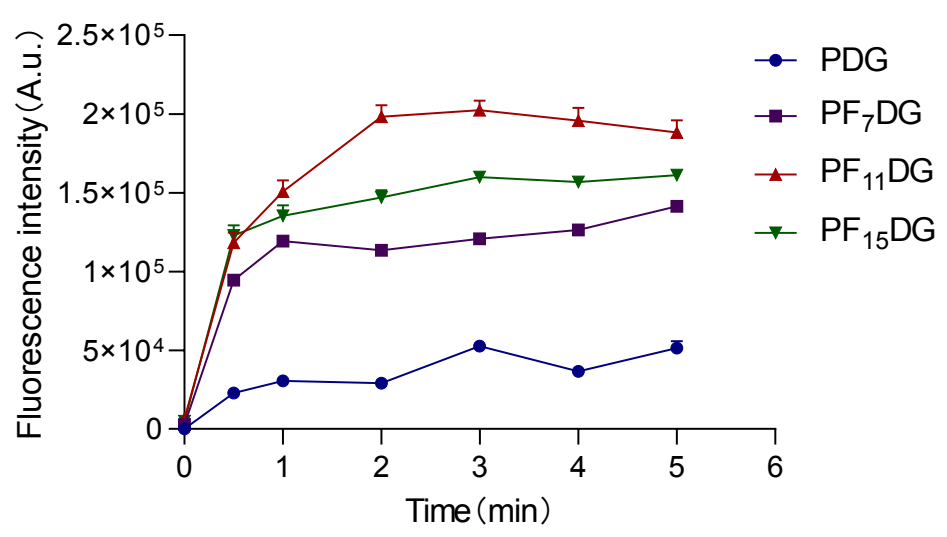

Figure S8 The in vitro ROS-producing activity of these nanovehicles upon laser irradiation at $1.0 \mathrm{~W} / \mathrm{cm}^{2}$ for $5 \mathrm{~min}$.
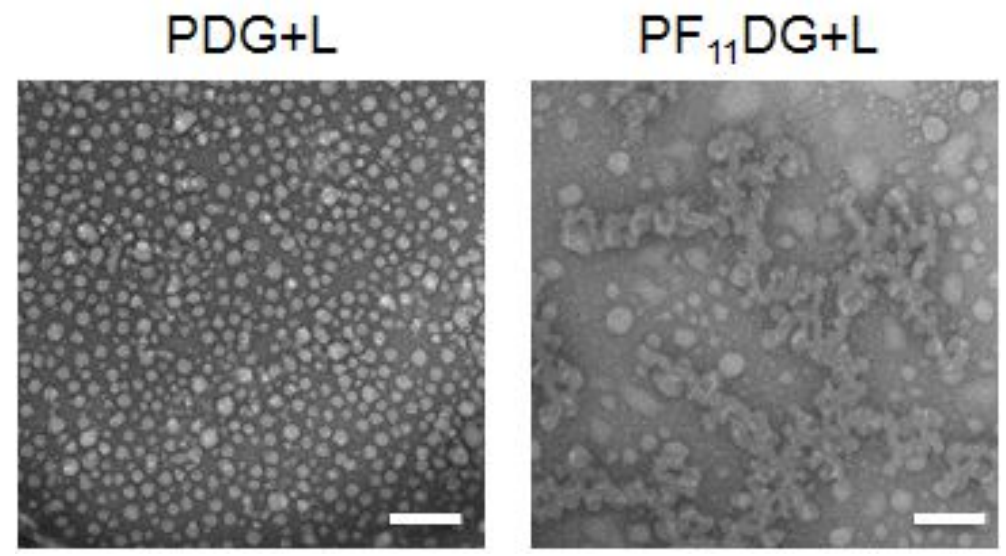

Figure S9 Typical TEM images of $\mathrm{PDG}$ and $\mathrm{PF}_{11} \mathrm{DG}$ after laser irradiation at 2.0 $\mathrm{W} / \mathrm{cm}^{2}$ for $5 \mathrm{~min}$, scale bar $=100 \mathrm{~nm}$. 


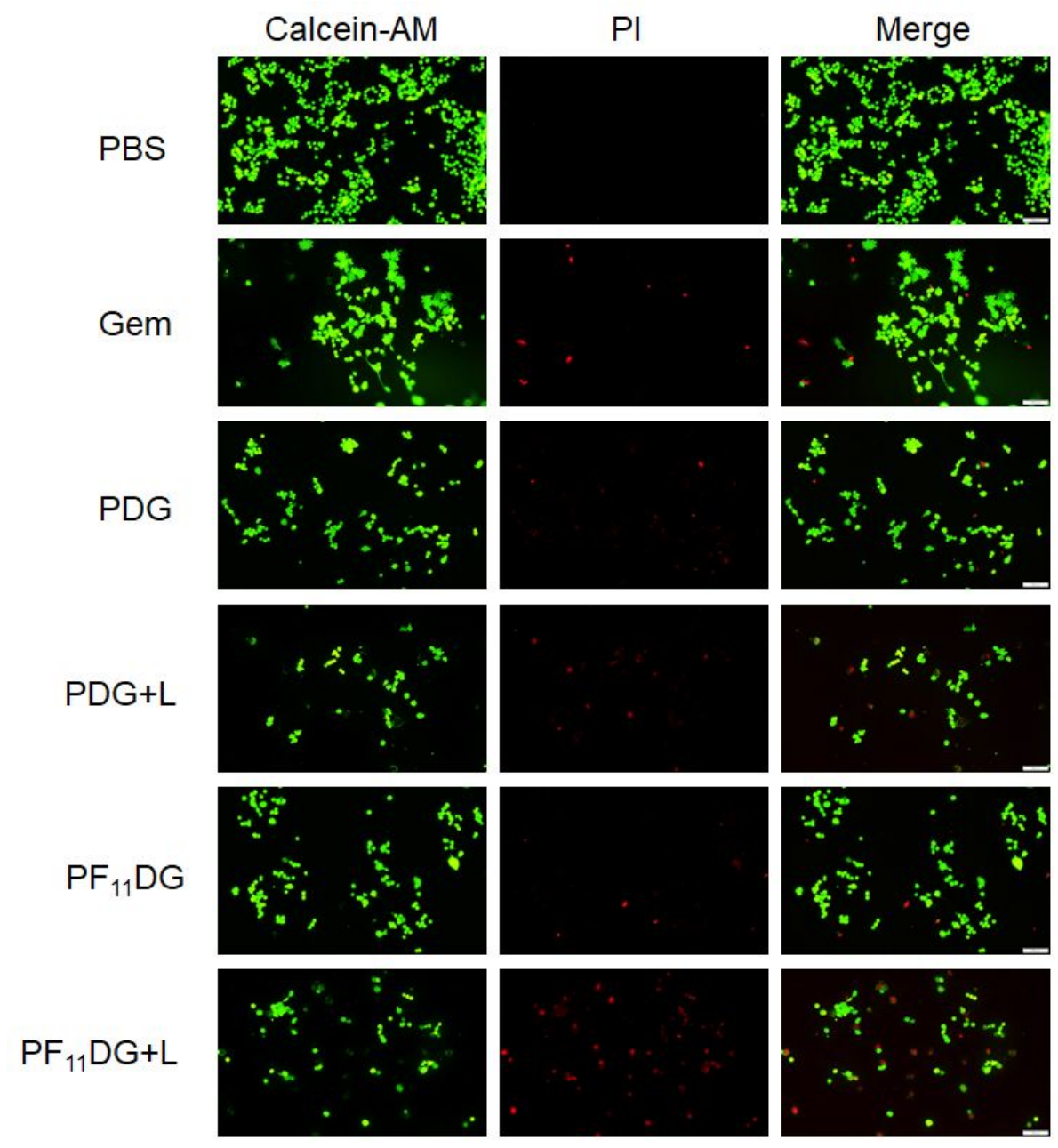

Figure S10 Live/dead assay of the 4T1 cancer cells, scale bar $=100 \mu \mathrm{m}$. Live cells were green signals from Calcein AM, while dead cells were red signals from propidium iodide (PI). 

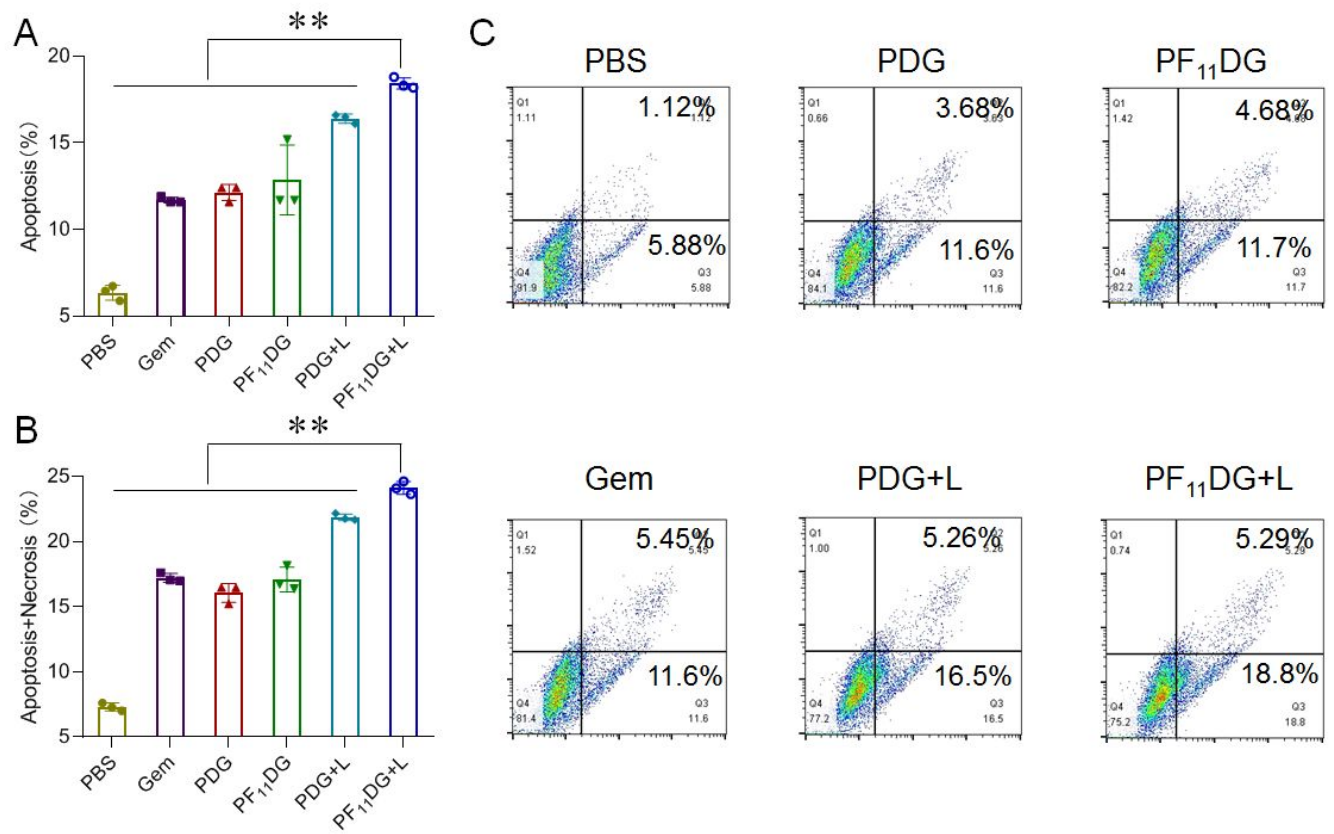

Figure S11 Apoptosis assay of the 4T1 cells from each treatment. (A) Percentage of early apoptotic cells $(\mathrm{n}=3),{ }^{* *} \mathrm{p}<0.01$; (B) Percentage of apoptosis + necrosis in 4 T1 cells from each treatment $(\mathrm{n}=3),{ }^{* *} \mathrm{p}<0.01$; (C) Flow cytometry analysis of $4 \mathrm{~T} 1$ cancer cells from each treatment.
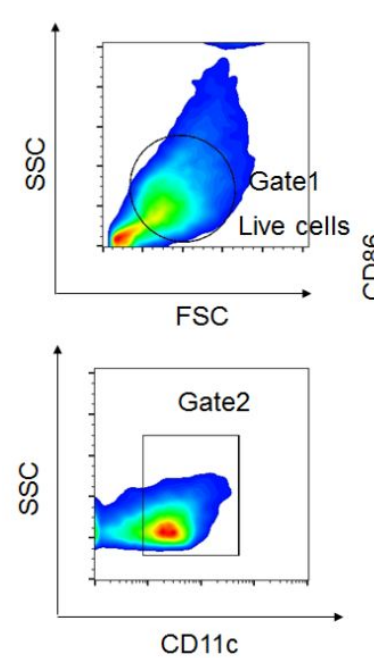
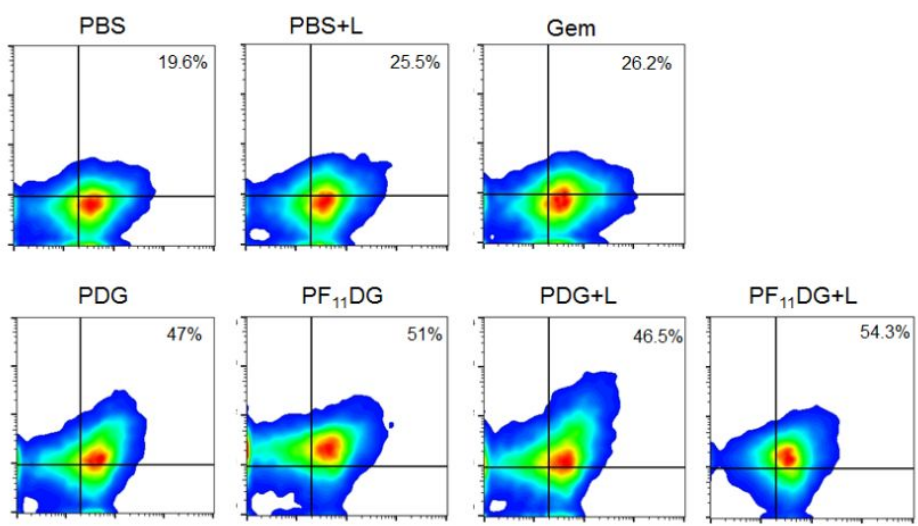

CD80

DC Maturation(\%) in tumor $=$ Gate $1 \times$ Gate2 $\times$ CD $80^{+}$CD $86^{+}$

Figure S12 The gating strategies and typical flow cytometry profiles of matured DCs in lymph nodes from each treatment, which was denoted as $\mathrm{CD} 11 \mathrm{c}^{+} \mathrm{CD} 80^{+} \mathrm{CD} 86^{+}$cells. 


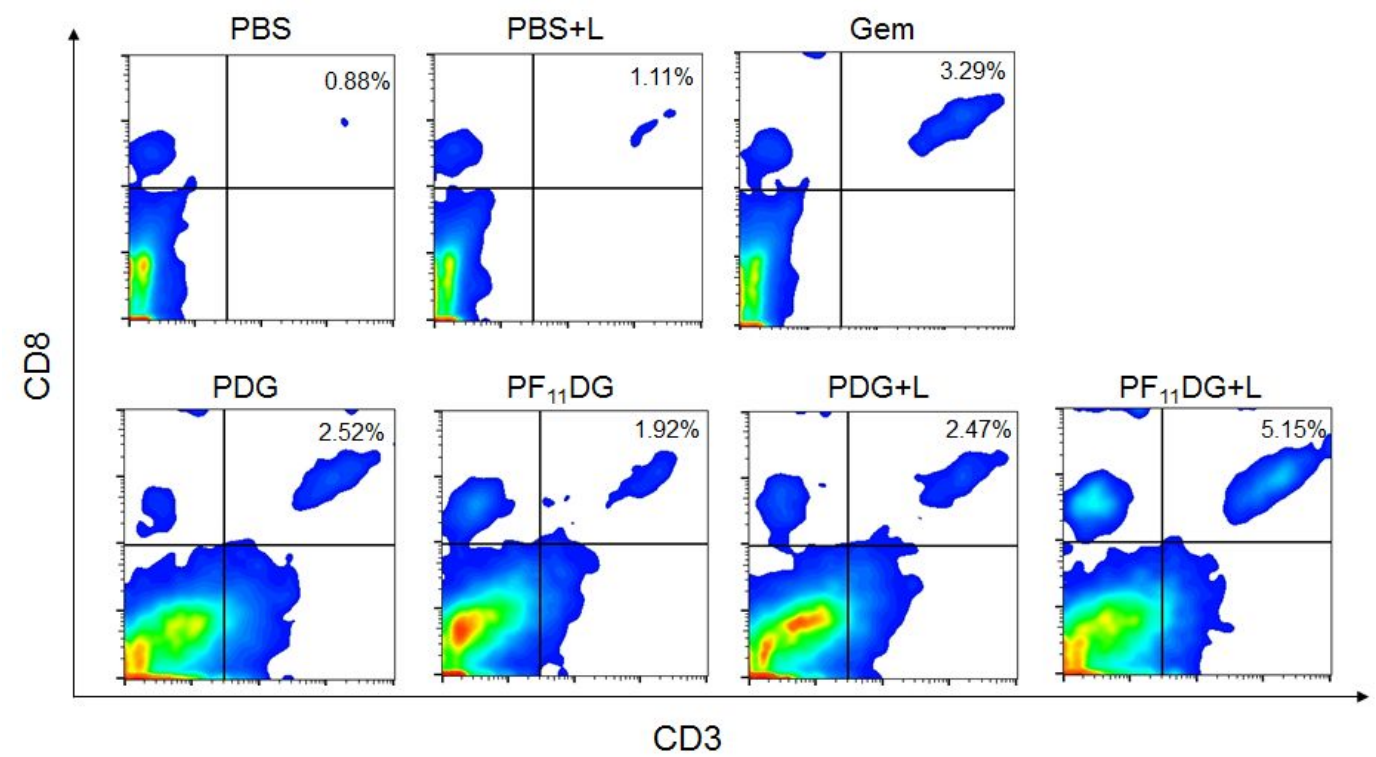

Figure S13 The typical flow cytometry profiles of $\mathrm{CD}^{+} \mathrm{CD}^{+} \mathrm{T}$ cells in tumor from each treatment.
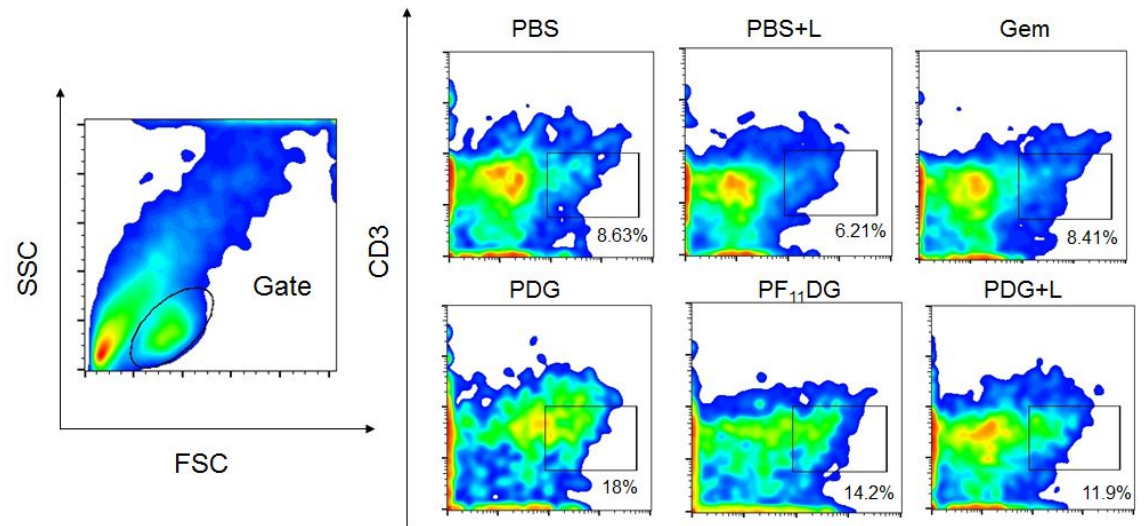

$P F_{11} D G+L$

$\mathrm{CD} 49 \mathrm{~b}$

CD3-CD49b ${ }^{+}(\%)$ in tumor $=$ Gate $\times C D 3-C D 49 b^{+}$

Figure S14 The gating strategies and typical flow cytometry profiles of NK cells in tumor from each treatment, which was denoted as $\mathrm{CD}^{-} \mathrm{CD}^{-} 4 \mathrm{~b}^{+}$cells. 

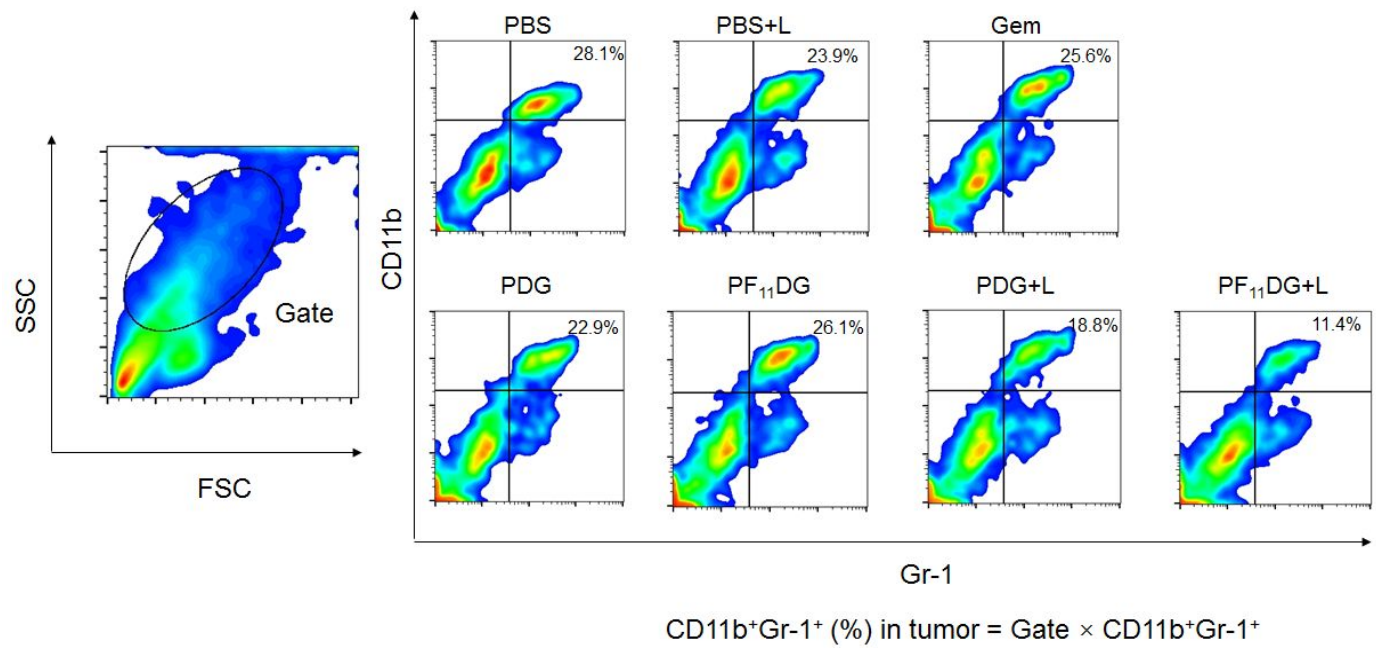

Figure S15 The gating strategies and typical flow cytometry profiles of MDSCs in tumor from each treatment, which was denoted as $\mathrm{CD} 11 \mathrm{~b}^{+} \mathrm{Gr}-1^{+}$cells.

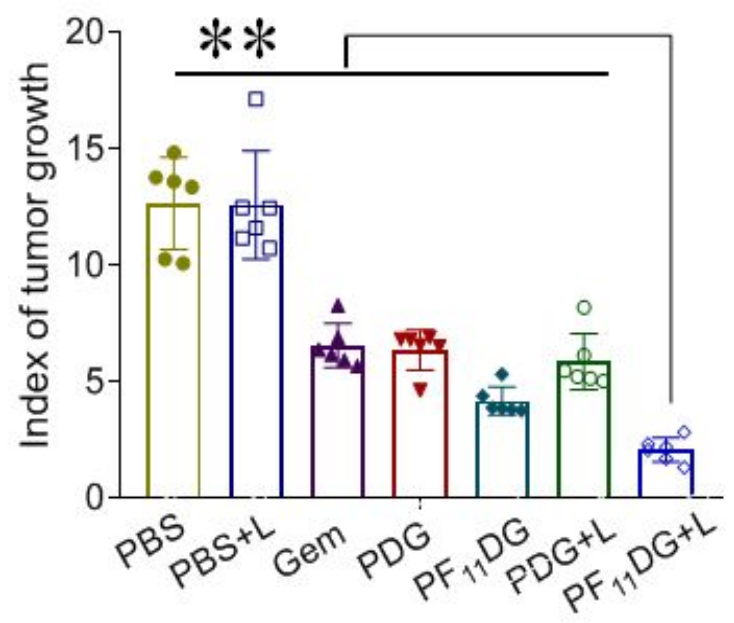

Figure S16 Tumor growth index of each treatment in the 4T1 breast cancer models, which was denoted as the tumor volume at the end time point compared to that at the beginning $(\mathrm{n}=6), * * \mathrm{p}<0.01$. 

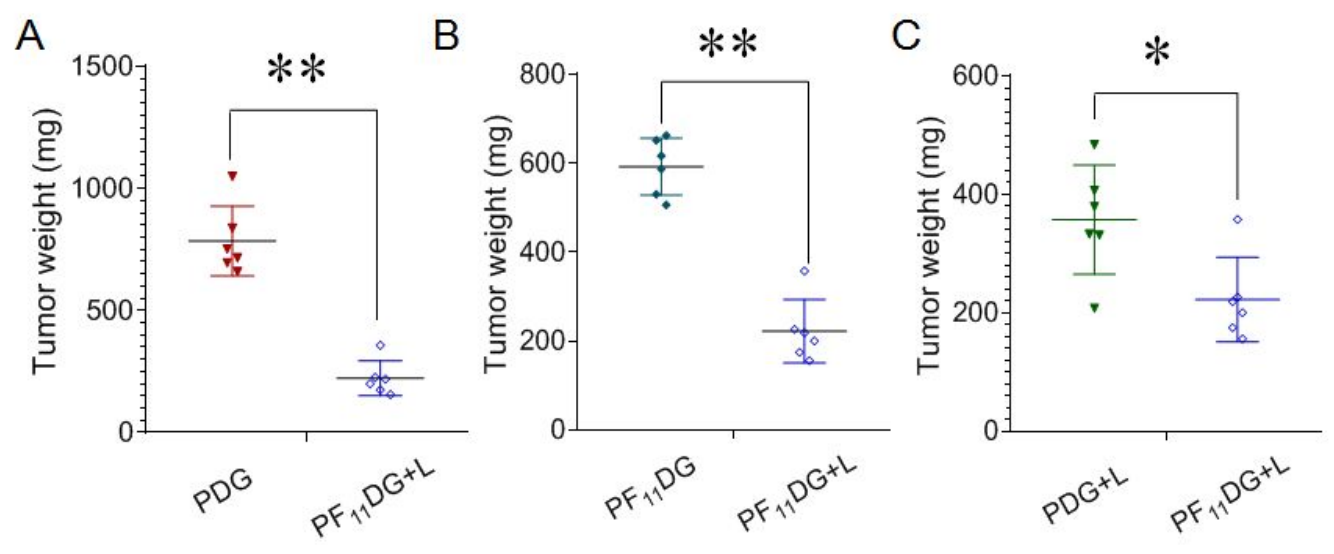

Figure S17 Tumor weight from the $\mathrm{PF}_{11} \mathrm{DG}+\mathrm{L}$ group compared with that from the $\mathrm{PDG}$ (A), $\mathrm{PF}_{11} \mathrm{DG}(\mathrm{B})$, and $\mathrm{PDG}+\mathrm{L}(\mathrm{C})$ treatments in $4 \mathrm{~T} 1$ cancer models $(\mathrm{n}=6),{ }^{*} \mathrm{p}<0.05 ; * *$ $\mathrm{p}<0.01$. 


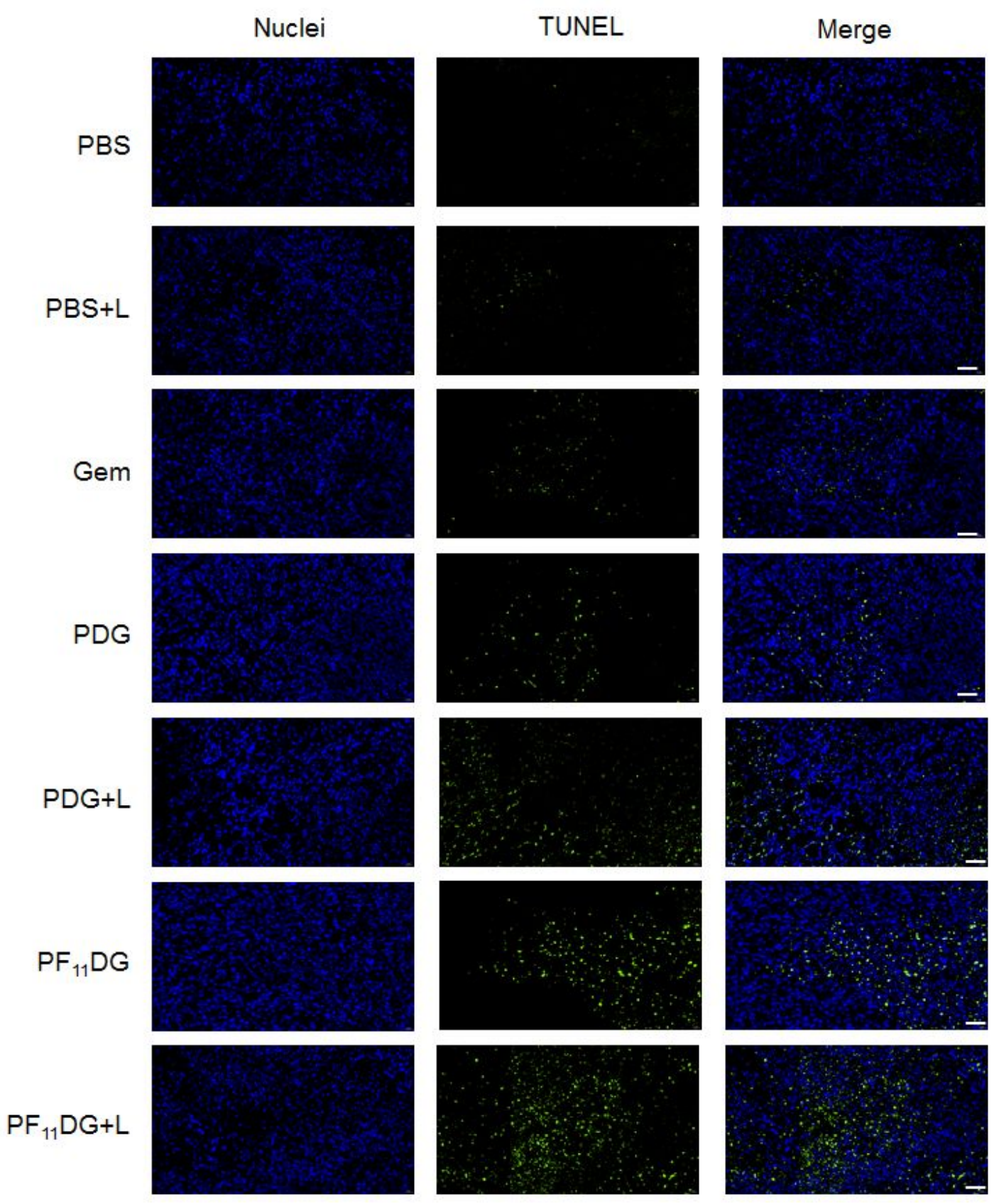

Figure S18 TUNEL assay of cell apoptosis in tumor from each treatment in 4T1 cancer models. The apoptotic cells were denoted as green signals, scale bar $=50 \mu \mathrm{m}$. 


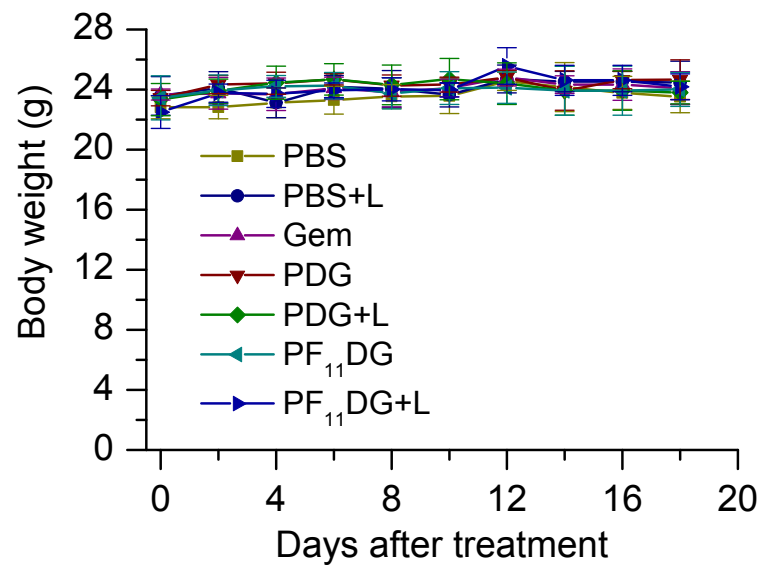

Figure S19 Body weights changes of the 4T1-induced tumor-bearing mice from each treatment $(n=6)$. 


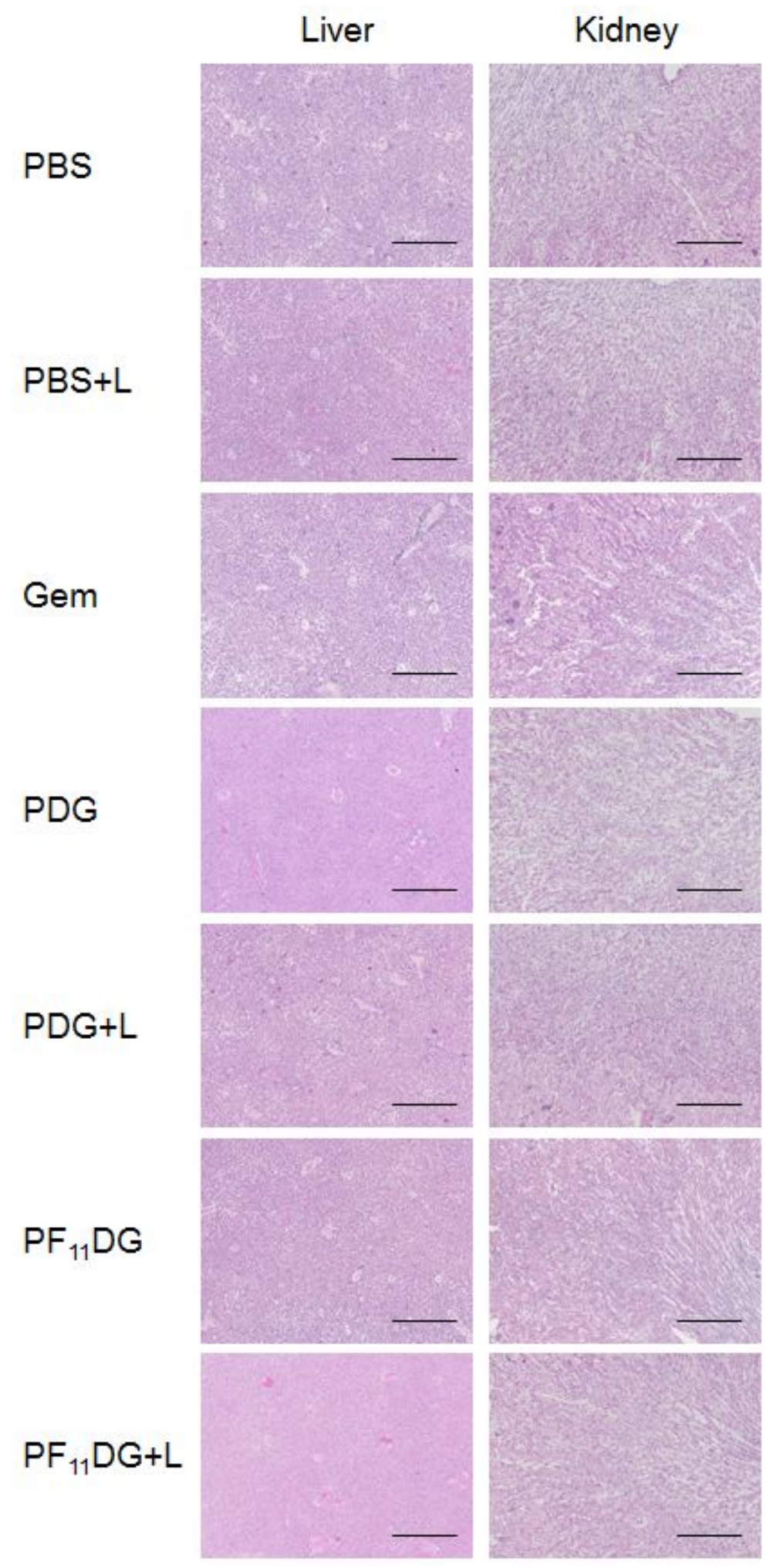

Figure S20 Histological examination of the liver and kidney from each treatment in 4T1 breast cancer models by HE staining, scale bar $=200 \mu \mathrm{m}$. 


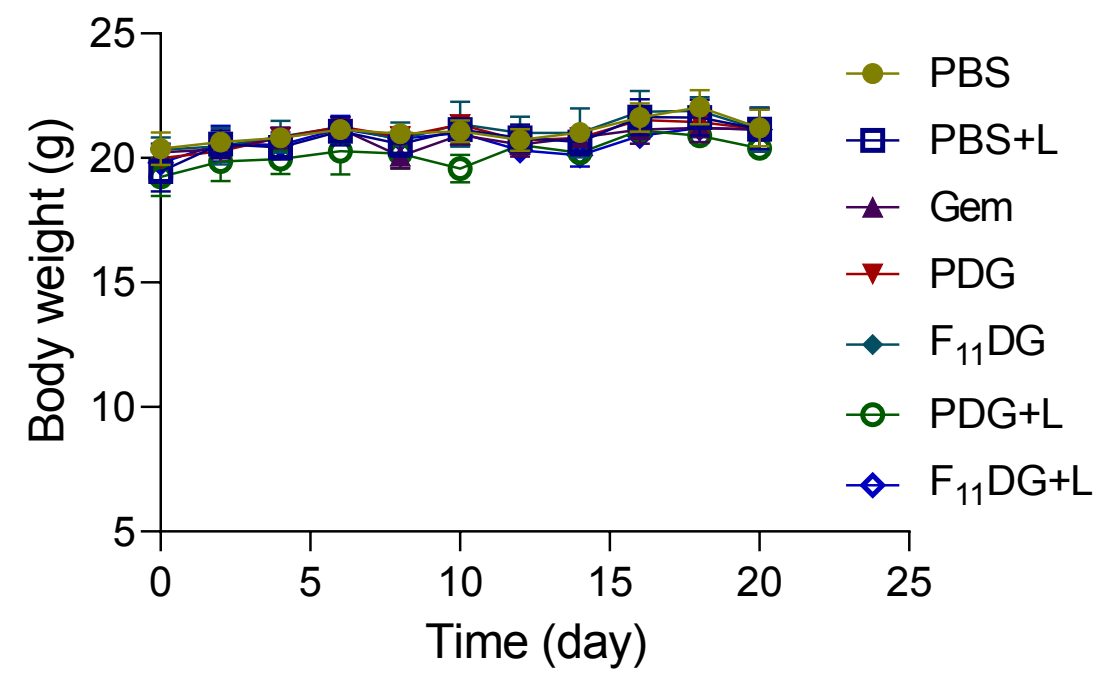

Figure S21 Body weights changes of the PANC02-induced tumor-bearing mice from each treatment $(n=5)$.

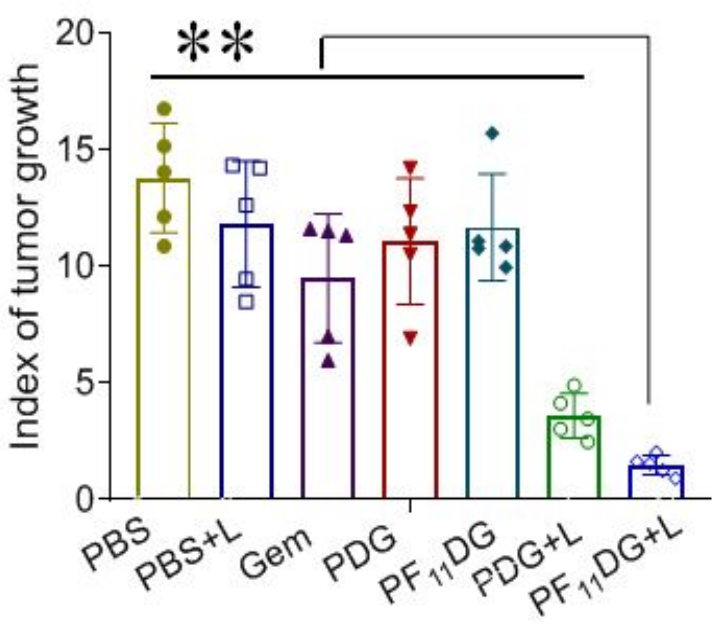

Figure S22 Tumor growth index of each treatment in the PANC02 pancreatic cancer models, which was denoted as the tumor volume at the end time point compared to that at the beginning $(\mathrm{n}=5),{ }^{*} * \mathrm{p}<0.01$. 

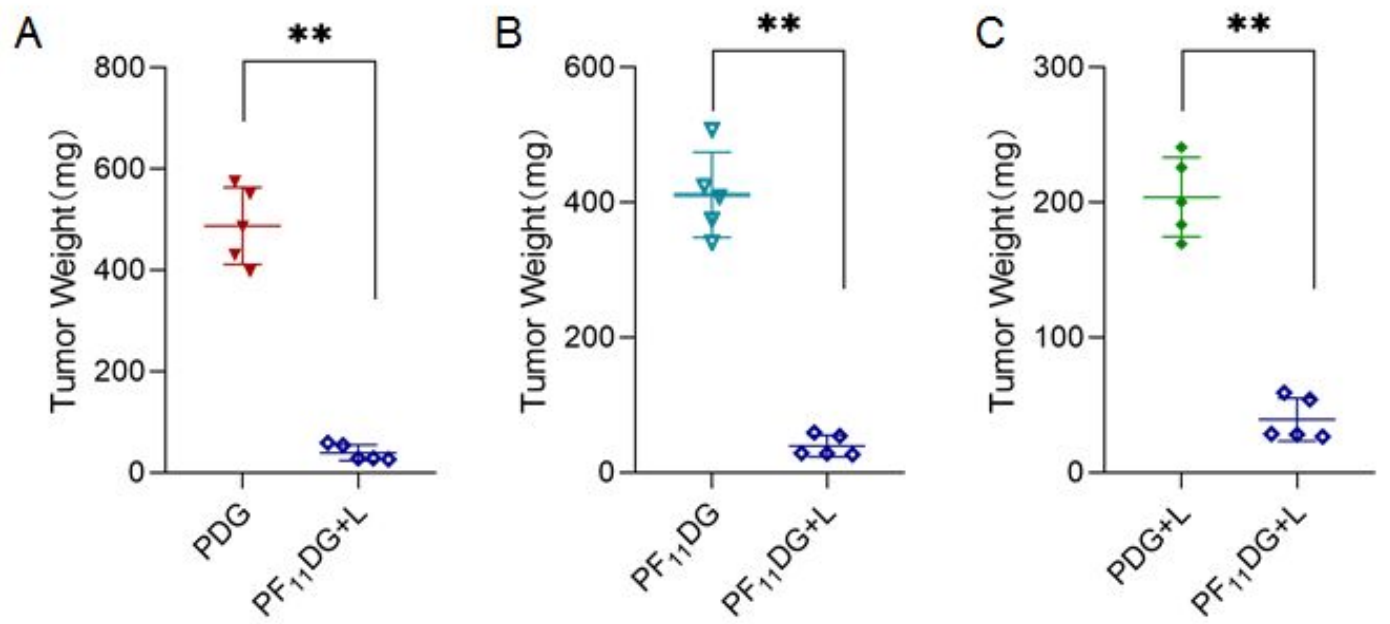

Figure S23 Tumor weight from the $\mathrm{PF}_{11} \mathrm{DG}+\mathrm{L}$ group compared with that from the PDG (A), $\mathrm{PF}_{11} \mathrm{DG}(\mathrm{B})$ and $\mathrm{PDG}+\mathrm{L}(\mathrm{C})$ treatments in $\mathrm{PANC} 02$ pancreatic cancer model $(\mathrm{n}=5)$, $* * \mathrm{p}<0.01$. 